\title{
Experimental Simulative Analysis Feed Point of Rectangular U Slot Microstrip Patch Antenna
}

\author{
Harleen Kaur \\ Assistant Professor \\ SBBSIET, Jalandhar
}

\author{
Balwinder Singh Dhaliwal \\ Assistant Professor \\ GNDEC, Ludhiana
}

\begin{abstract}
The main focus of this paper is to study and analyze how the performance of rectangular U slot antenna is affected by the parameters like Feed point position. The work presented herein is a simulation based study. Experimentally, it has been revealed that variations in parameters such as the width and length of the U-slot, height and size of the patch, probe size and location as well as substrate permittivity can dramatically change the antenna's behavior. Till date, no analytical methods have been developed that accurately relate the complex relationships between the antenna dimensions and individuality. This paper describes the behavior of antenna with change of feed point position. A numerical solution is obtained by varying the various positions of feed point along all the axis and the effect of $U$ slot position on various antenna output parameters is analyzed.
\end{abstract}

\section{Keywords}

Microstrip Patch Antenna, Return Loss, Gain, Bandwidth.

\section{INTRODUCTION}

With the increased necessities for personal and mobile communications, the demand for smaller and low-profile antennas has brought the Microstrip Antennas (MSA) to the forefront. Since, MSA are known to possess properties like low size, weight, cost, performance, ease of installations, these antennas provide a very good performance [1]. MSA are also known as patch antenna due to the radiating patch on one side of the dielectric substrate and ground on other side. The physical characteristics of MSA are compatible for use in mobile phones, Bluetooth personal networks and wireless local networks [2]

Even though these antennas have lots of advantages but it also suffers from few shortcomings like small efficiency, low power, very narrow frequency bandwidth [3]. The basic and most commonly used MSA is rectangular MSA. The MSA suffer from the major disadvantage of narrow bandwidth [4]. A number of methods have been worked out by the researchers to overcome the limitations of MSA. The limitations of MSA can be prevailed over by increasing the permittivity of the substrate or by increasing the height of the patch. However, the results of both of these methods are inadequate since increasing patch height results in modifying the low-profile feature of the patch whereas the implementation of second is subject to material availability and suitability [5]. Another technique includes the use of the parasitic elements lying on same layer or another layer (stacked). The aperture coupled excitations also used to achieve the wider bandwidth but this method is having a complication of fabrication process [6].

The various slot shapes are available to fulfill the requirement of improvement in bandwidth. The etching of $U$ slot on the
Microstrip patch is considered to be a simple design [7] .Such a design does not make use of stacked or coplanar parasitic patches because either of these increases the thickness or the lateral size of the antenna. So, while changing the current distribution on the Microstrip patch enhancing the impedance bandwidth with sometimes more than one resonant frequency are obtained [8]. The loading of slot on the radiating patch results in increase of the current length that results in lowering fundamental resonance frequency which corresponds to reduced antenna size when compared to conventional patch antenna for a given resonant frequency.

\section{RELATED WORK}

The earlier analysis and the empirical technique of $U$ slot antenna are based on dimensional invariance relationships observed in the U-slot geometry and empirical design equations [9]. The strength of this method is that it converges on the optimized design quickly - if the desired frequency lies in the range in which the design equations are reliable. The constraint of former method is that the design equations were developed for specific values of substrate permittivity and thickness. The impracticality of deriving similar equations for all possible combinations of permittivity and thickness limits the usefulness of this technique. Also rather than chamfering any corner of the probe feed square patch microstrip antenna the symmetrical U-slot can be employed to produce the two orthogonal modes for circular polarization. The parametric study has also been carried out to analyze the effects caused by different arm lengths of the U-slot. Both experimental and theoretical results of the antenna had been verified [10]. The physical parameters for example length of $U$ slot, width of $U$ slot, height and size of patch, probe location, substrate permittivity can greatly affect the antenna's performance[6]. In this paper the effect of various values of slot length and slot width on return loss and gain has been analyzed. After this the numerical solution is obtained for these values. The characteristics of the classical stacked and U-slot patch antenna were also examined.

\section{VARIATION OF FEED POINT POSITION OF U SLOT ANTENNA.}

In this paper, the effect of variation of feed point position of rectangular U slot antenna's (shown in Fig 3.1) performance is to be analyzed. Here, the feed point is varied along both the axis. A numerical solution of the antenna is to be obtained for various values of the feed point position and the effect of these parameters on the return loss, gain, bandwidth, frequency, VSWR of the antenna are studied. 

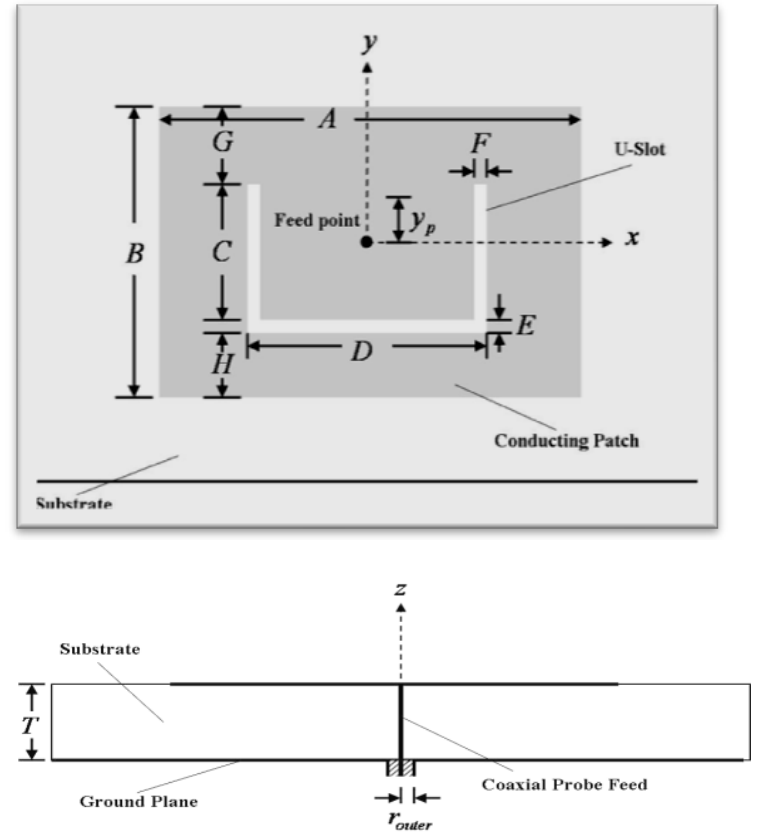

Fig. 1 Geometry of the Rectangular U-Slot Microstrip Patch Antenna [9]

Table 1. Dimensions and Material Properties of the Initial U-Slot Antenna used in the Parametric Studies

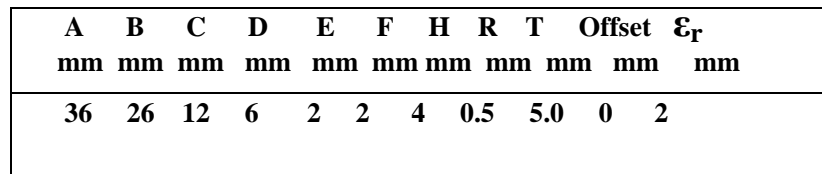

The antenna geometry provided in [9] served as a basis for the analysis of $U$ slot rectangular antenna which was carried out using a method of moments simulation package. The initial geometric and material properties are provided in table 1.

Several parameters are found to have significant effects on antenna's behaviour e.g. substrate thickness, slot width etc. Here the position of Feed point is varied to evaluate the effect on antenna's behaviour.

\subsection{Investigating the Relationship between the Feed Point Position and the \\ Parameters of the Patch}

The variation of feed point is also known to affect the behavior of the antenna. Here, the feed point is varied along both the axis. The variation range of $\mathrm{x}$-axis is from 0.35 to 6 and similarly the range considered for variation along y axis is from 0 to 5 . The feed point variation affects the parameters like return loss, gain, bandwidth, voltage wave standing ratio. Table 1 represents the variation of feed points and its corresponding antenna geometries.
Table 2 Feed Point Variation of U Slot Antenna

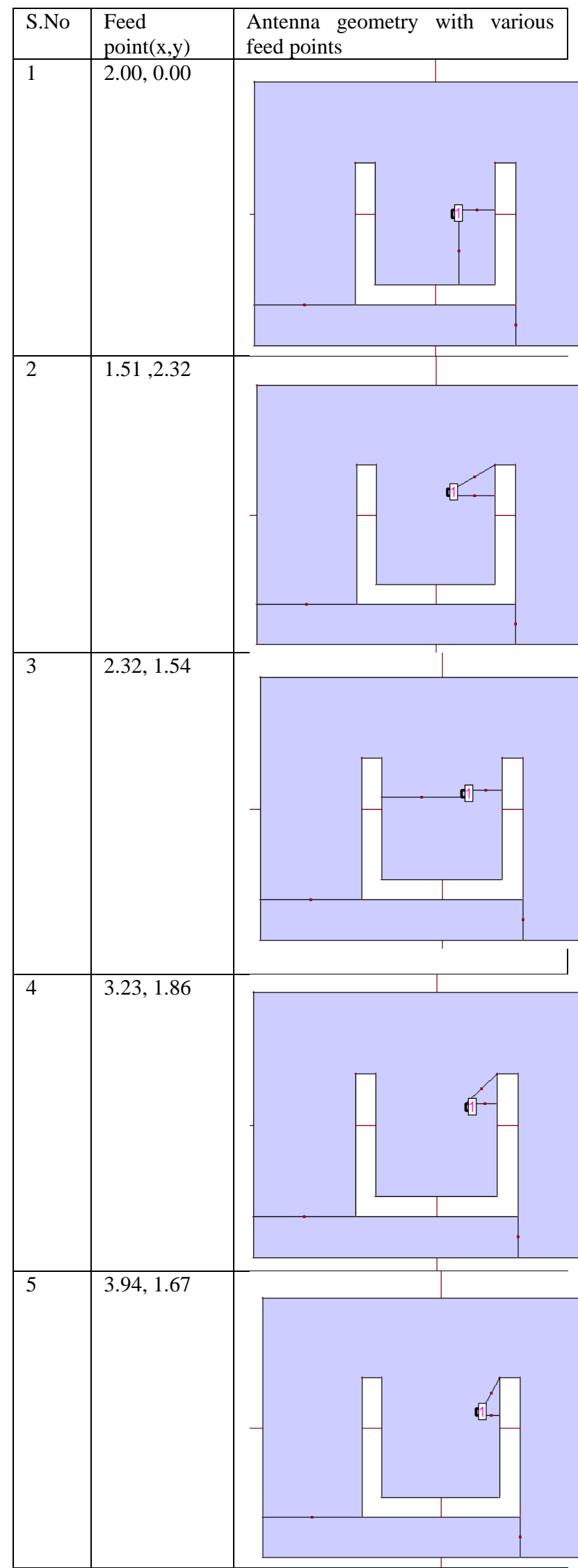



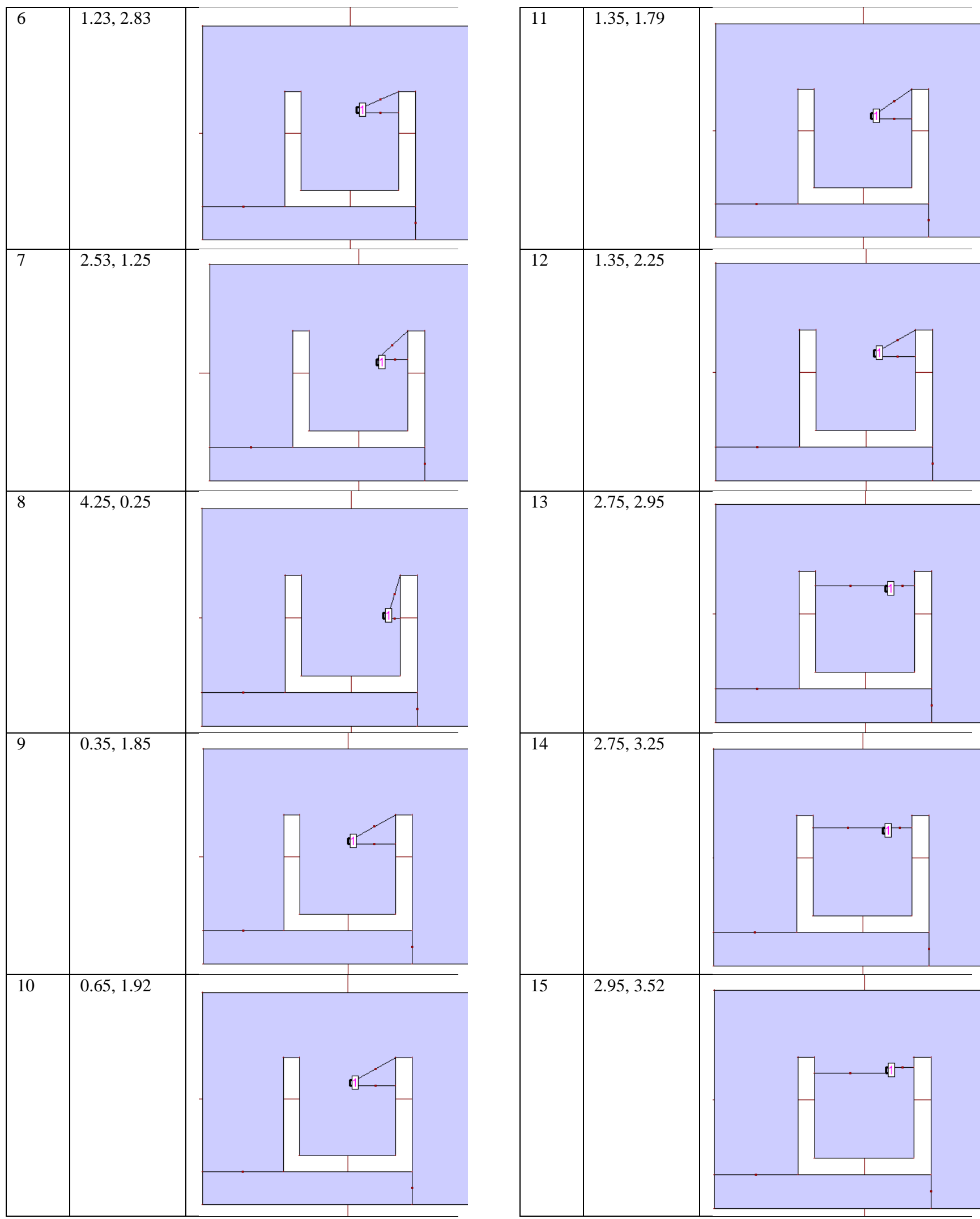

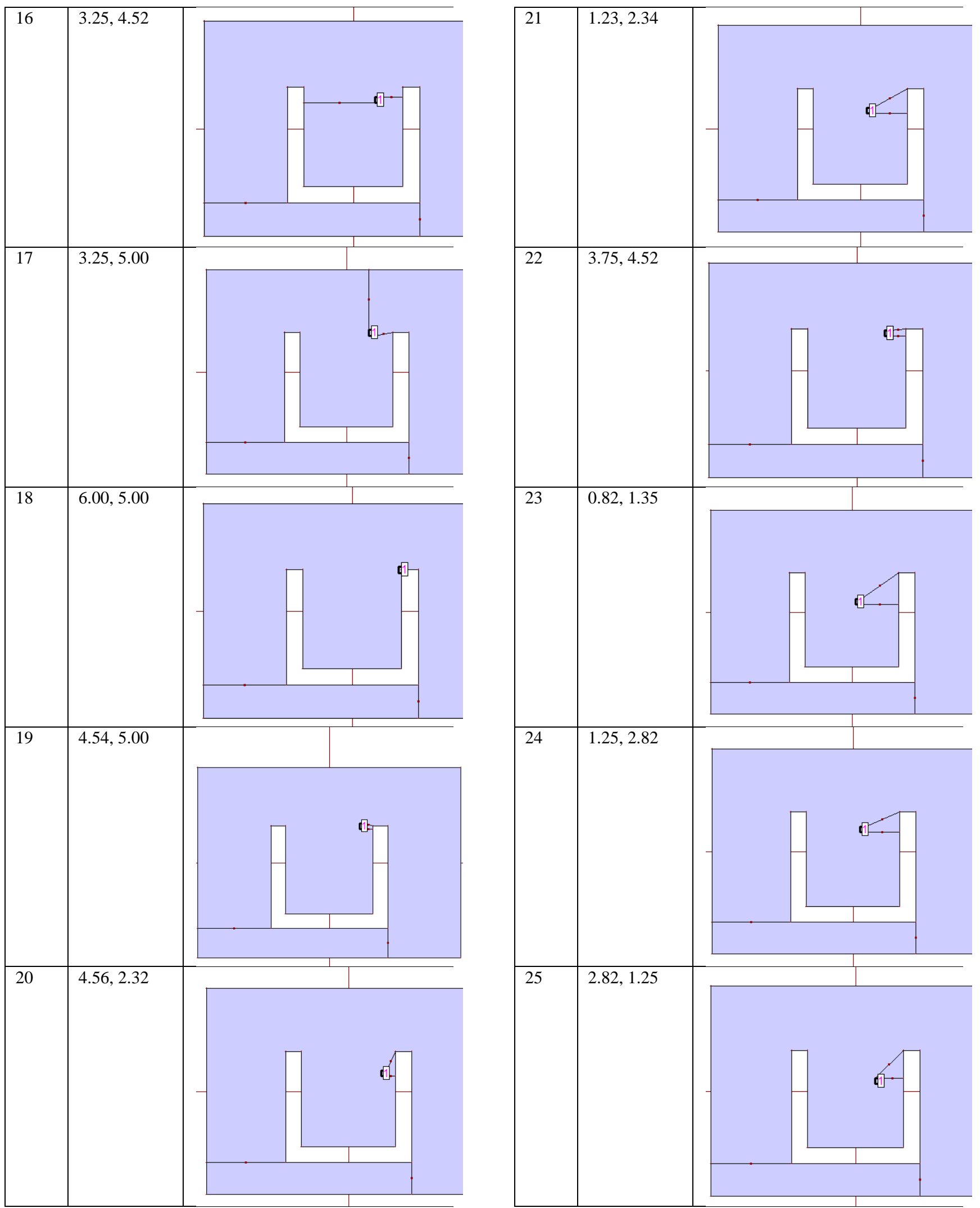


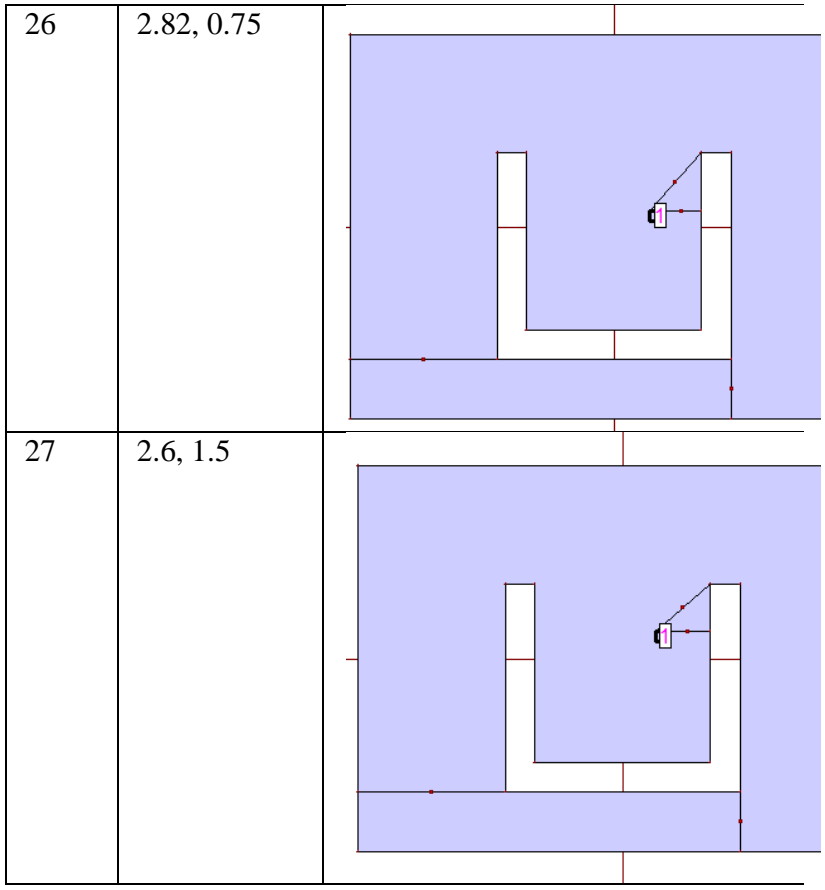

The variation of feed point affects the output parameters such as frequency, return loss, gain, VSWR and bandwidth. The table 2 shows the effect on various parameters which is caused when the feed point is varied along $\mathrm{x}$ and $\mathrm{y}$ axis respectively.

From the simulations given in table 2, it is seen that the better performance of antenna can be achieved by varying the feed point. Here the feed point is randomly varied along positive $\mathrm{x}$ and $y$ axis. It is observed that at the feed point of $(2.32,1.54)$, $(2.53,1.25),(0.35,1.85),(1.35,1.79),(2.82,1.25),(2.6,1.5)$, the output parameters has been improved in case of return loss by the value of $-56.97,-32.11,-29.25,-29.97,-32.90$, 29.2 respectively. Similarly the other factors like gain is also improved at these points while at the same time the bandwidth is reducing with a small difference. On the other hand, at the feed point $(2.75,3.25),(2.95,3.52)$, $(3.52,4.52),(3.25,5.00),(4.54,5.00),(3.75,4.52)$, there is a degradation in the output parameters of the antenna. The factors like return loss, gain, bandwidth are decreasing in their performance.

\section{CONCLUSION}

It is observed that the improved results of all the parameters can be achieved from the range of 0.35 to 2.9 in case of $\mathrm{x}$ axis and 0.75 to 1.9 in case of y axis. It is also seen that as the feed point is shifted away from the origin, the performance of all factors decreases abruptly. In the case of feed point of 2.32, 1.54 the return loss and resonant frequency can be reduced to 56.97 and 3.79 respectively. Also the gain can be increased upto $6 \mathrm{~dB}$. Therefore it is concluded that it shows the better results in comparison to the reference antenna [4] having the parameters of return loss $=14 \mathrm{db}$, gain $=5 \mathrm{db}$, frequency $=$ $4.0 \mathrm{GHz}$.

Table 2 Feed Point Variation of Rectangular U SlotAntenna.

\begin{tabular}{|c|c|c|c|c|c|c|}
\hline S. & Fee & Fee & Resonan & Retur & Gai & Bandwid \\
No & $\mathrm{d}$ & $\mathrm{d}$ & $\mathrm{t}$ & $\mathrm{n}$ & $\mathrm{n}$ & th \\
$\cdot$ & Poi & Poi & Frequen & Loss & $(\mathrm{dBi}$ & $(\%)$ \\
& nt x & nt y & $\begin{array}{c}\text { cy } \\
(\mathrm{GHz})\end{array}$ & $(\mathrm{dB})$ & ) & \\
& & & & & \\
\hline
\end{tabular}

\begin{tabular}{|c|c|c|c|c|c|c|}
\hline 1 & 2.00 & 0.00 & 3.97 & $\begin{array}{c}- \\
14.84\end{array}$ & 5.07 & 9.01 \\
\hline 2 & 1.51 & 2.32 & 3.73 & $\begin{array}{c}- \\
17.94\end{array}$ & 5.21 & 9.01 \\
\hline 3 & 2.32 & 1.54 & 3.79 & $\begin{array}{c}- \\
56.97\end{array}$ & 5.98 & 8.13 \\
\hline 4 & 3.23 & 1.86 & 3.73 & $\begin{array}{c}- \\
19.80\end{array}$ & 5.71 & 6.76 \\
\hline 5 & 3.94 & 1.67 & 3.78 & $\begin{array}{c}- \\
22.69\end{array}$ & 5.95 & 7.02 \\
\hline 6 & 1.23 & 2.83 & 3.73 & $\begin{array}{c}- \\
13.03\end{array}$ & 5.42 & 4.39 \\
\hline 7 & 2.53 & 1.25 & 3.79 & $\begin{array}{c}- \\
32.11\end{array}$ & 5.96 & 8.33 \\
\hline 8 & 4.25 & 0.25 & 3.88 & $\begin{array}{c}- \\
19.89\end{array}$ & 5.34 & 8.79 \\
\hline 9 & 0.35 & 1.85 & 3.77 & $\begin{array}{c}- \\
29.25\end{array}$ & 5.50 & 7.7 \\
\hline 10 & 0.65 & 1.92 & 3.77 & $\begin{array}{c}- \\
27.31\end{array}$ & 5.42 & 7.53 \\
\hline 11 & 1.35 & 1.79 & 3.78 & $\begin{array}{c}- \\
29.97\end{array}$ & 5.58 & 7.94 \\
\hline 12 & 1.35 & 2.25 & 3.75 & $\begin{array}{c}- \\
18.81\end{array}$ & 5.56 & 6.63 \\
\hline 13 & 2.75 & 2.95 & 3.69 & $\begin{array}{c}- \\
10.74\end{array}$ & 5.22 & 2.23 \\
\hline 14 & 2.75 & 3.25 & 3.69 & -8.88 & 4.50 & 0.57 \\
\hline 15 & 2.95 & 3.52 & 3.66 & -7.38 & 4.42 & 0.69 \\
\hline 16 & 3.25 & 4.52 & 2.87 & -5.06 & 2.58 & 1.00 \\
\hline 17 & 3.25 & 5.00 & 2.86 & -4.87 & 2.37 & 0.71 \\
\hline 18 & 6.00 & 5.00 & 2.37 & $\begin{array}{c}- \\
14.73\end{array}$ & 5.54 & 2.13 \\
\hline 19 & 4.54 & 5.00 & 2.34 & -5.8 & 4.86 & 0.54 \\
\hline 20 & 4.56 & 2.32 & 3.71 & $\begin{array}{c}- \\
12.38\end{array}$ & 1.63 & 3.83 \\
\hline 21 & 1.23 & 2.34 & 3.74 & $\begin{array}{c}- \\
18.29\end{array}$ & 5.38 & 6.44 \\
\hline 22 & 3.75 & 4.52 & 2.86 & -5.09 & 2.59 & 0.13 \\
\hline 23 & 0.82 & 1.35 & 3.82 & $-\overline{-}$ & 4.93 & 8.63 \\
\hline 24 & 1.25 & 2.82 & 3.70 & $\begin{array}{c}- \\
12.85\end{array}$ & 5.40 & 4.32 \\
\hline 25 & 2.82 & 1.25 & 3.79 & -32.9 & 5.38 & 7.24 \\
\hline 26 & 2.82 & 0.75 & 3.83 & $\begin{array}{c}- \\
22.34\end{array}$ & 5.81 & 8.63 \\
\hline 27 & 2.6 & 1.5 & 3.77 & -29.2 & 5.64 & 7.84 \\
\hline
\end{tabular}

\section{REFERENCES}

[1] Balanis, C.A, Antenna Theory Analysis and Design, Wiley Publishers, (2005) 
[2] Ansari, J.A. and Mishra,A. Analysis of L-Shaped Slot Loaded Circular Disk Patch Antenna for Satellite and Radio Telecommunication, Wireless Personnel Communication, (2012), vol. 70, pp. 927-943.

[3] Kumar, G. and Ray, K.P. Broadband Microstrip Antennas, Artech House, Waterhouse, R.B.J (2003).

[4] J. A. Ansari, R. B. Ram, and P. Singh. Analysis of a gapcoupled stacked annular ring microstrip antenna, Progress in Electromagnetics Research B, (2008) Vol. 4, $147-158$

[5] S. S. Yavalkar, R. T. Dahatonde. And S. S. Rathod. Parametric Study of Rectangular Microstrip Patch Antenna, IOSR Journal of Electronics and Communication Engineering (IOSR-JECE) (Mar. - Apr. 2013), Volume 5, Issue 2 pp 49-53.

[6] Surmeli, K. and Turetken, B .U-Slot Stacked Patch Antenna. Using High and Low Dielectric Constant Material Combinations in S-band, (2011).
[7] Uzer ,M.S. , Uzer, D. , Yilmaz, N. and Gultekin, S.S. Bandwidth Modelling of U Slot Rectangular Microstrip Antenna with Artificial Neural Networks" Proceedings of Progress in Electromagnetic Research Symposium, Kuala Lumpur, MALAYSIA, (2012), pp. 559-563.

[8] Uzer, D. ,Uzer ,M.S. , Gultekin, S.S. and Yilmaz, N. Effect of U Slot Applications on Circular Microstrip PatchesProceedings of Progress in Electromagnetic Research Symposium, Kuala Lumpur, MALAYSIA, (2012), pp. 554-558

[9] Weigand ,S. and Huff, G.H. Analysis and Design of Broad-Band Single- Layer Rectangular U-Slot Microstrip Patch Antennas, IEEE Transactions on Antenna and Propagation, (2003), vol .51, No. 3, pp. 457-468.

[10] Tong, K.F. and Wong, T.P. Circularly Polarized U-Slot Antenna IEEE Transactions on Antenna and Propagation, (2007), vol. 55, No. 8, pp.2382-2385. 